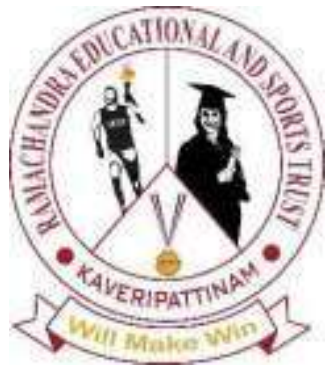

Recent trends in Management and Commerce

Vol: 2(3), 2021

REST Publisher

ISBN: 978-81-936097-6-7

Website:http://restpublisher.com/book-series/rmc/

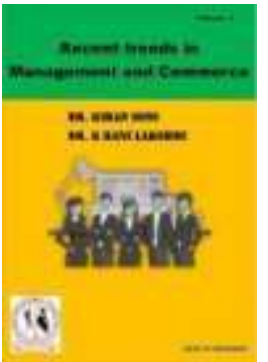

\title{
Artificial Intelligence And Communication Management : A Study On Communication Practitioners
}

\author{
Amrit Kaur, Poonam Verma \\ Assistant Professor, USB-Commerce, Chandigarh University, Punjab, India. \\ Email: $\underline{\text { amrit.usb@cumail.in }}$
}

\begin{abstract}
Development of society in terms of technology, especially the digitization and automation of economy is going to have the impact on every profession and businesses. Artificial Intelligence in products and services have been transmuted from theoretical concept into actual reality because of the high-speed growth and evolution of deep learning. The usage of AI has both impacts positive as well as negative that includes the threat of changes and even extinction of some professions also. Artificial intelligence might have the impact on the communication practitioners tremendously but on this topic very less research is being done. The main aim of this research paper is to investigate the impact of Artificial Intelligence on the communication practitioners, challenges and risk they might face. To achieve the objective of this research paper quantitative research was done and 150 respondents' responses were recorded via a questionnaire. Respondents included journalists, advocates, professors, managers and principals. The study highlighted that practitioners were having limited knowledge about AI , there was a element of uncertainty in the responses. The study is limited to Punjab only due to the ongoing pandemic situation, so because of which my study cannot be taken as statistically correct for communication practitioners because of the demographic limitation and time constraint.
\end{abstract}

Keywords: Artificial Intelligence, Communication practitioners, Leadership and Management

\section{Introduction}

The electronic evolution of businesses has the major implications on business life cycle, society and management. Artificial Intelligence is day by day becoming a common topic not only in industries like manufacturing, services or management but it has also become as a common thing in layman's normal daily routine. Nowadays it is common to see people using Amazon's Alexa or google assistant or even siri for their daily chores. Presently, artificial intelligence advancement strategies are being formulated by different countries like India, UK, USA, Japan, China and many more with the purpose of dominating advanced and developed communication and information technologies. Nowadays this Artificial intelligence topic is becoming more trendy in the academia, researchers from every field and specialization they are giving inputs on this topic. As per AI Index 2021 there were effects of COVID 19 on AI development from different perspectives. Due to COVID-19 a good number of academician started participating in Artificial Intelligence related research conferences as this pandemic has forced seminar and conferences to shift to virtual formats, which in turn has led to vital increase in attendance. Some communication practitioners are recommending this area to be given more attention and we should try to understand how the normal people interact with Artificial Intelligence and what their implications are. In this research paper, quantitative research is done among 100 respondents on the basis of the some research questions.

\section{Theoretical Framework}

In the older time period, innovation have generally always created more and more jobs which lead to enhancement in the way of living ( Brynjolfsson and McAfee, 2014). As per Brynjolfsson and McAfee, 2014, contemporary wave of AI will have huge impact on the different practitioners. Artificial Intelligence is being referred as mechanism or machine having the capacity to imitate intellectual and rational human tasks (Jarrahi, 2018) David Poole and Alan Mackworth 2017 defined artificial intelligence as "computational agents that act intelligently". According to Zerfass, Hagelstein and Tench, communication practitioners disclosed revealed they have a inadequate comprehension of Artificial Intelligence and anticipated the technology to have the impact on this profession as a complete in excess how their organisations work or they work. Artificial Intelligence is a technology which is useful for professionals to take decision and managers should take Artificial Intelligence as a colleague (Dejoux \& Léon,2018). Dawar and Bendle (2018) states that AI will have the impact on the marketing and they also stated that Artificial Intelligence assistants will reconstruct the way companies or organisations will connect or associate with their customers. To recapitulate, role of Artificial Intelligence in communication practitioners' lives will depend on the understanding 
of concept by practitioners. Amrit Kaur.et.al/Recent trends in Management and Commerce Vol: 2(3), 2021:5-7

inconsistent knowledge among the communication practitioners.

\section{Research Methodologies}

To conduct the research, quantitative research technique was used. The data was collected from 150 respondents and respondents were from various professions, i.e. journalists, advocates, professors, managers and principals, with varied years of experience. Questionnaire included eight questions on the basis of which analysis was done. Data was collected by mailing the questionnaire to the potential respondents and out of the 150 respondents, 62 were females and 88 were males. $60 \%$ of the respondents were having bachelor degrees, 37\% had master degrees and rest 3\% were doctorates. Data was analyzed using SPSS software.

\section{Findings}

The first question which was to check the knowledge level of the respondents regarding Artificial Intelligence. They were asked to rate on their answer on 5 point likert scale. Their responses are tabulated below:

\begin{tabular}{|l|l|l|l|l|l|}
\hline Valid & Frequency & Percent & Valid Percent & Cumulative percent \\
\cline { 2 - 6 } & Not at all familiar & 0 & 0 & 0 & 0 \\
\cline { 2 - 6 } & Slightly familiar & 15 & 10 & 10 & 10 \\
\cline { 2 - 6 } & Moderate familiar & 75 & 50 & 50 & 60 \\
\cline { 2 - 6 } & Very familiar & 45 & 30 & 30 & 90 \\
\cline { 2 - 6 } & Extremely familiar & 15 & 10 & 10 & 100 \\
\hline & Total & 150 & 100 & 100 & \\
\hline
\end{tabular}

For this research study I have selected only those respondents who had some knowledge about the concept. Next question which was asked to communication practitioners was about the usage of Artificial Intelligence in their daily life. After analyzing the responses of the respondents approximately $80 \%$ of the respondents were using artificial intelligence in their daily in one way or the another. Rests $20 \%$ have declined the usage in their daily personal life. Then the communication practitioners were asked about the question on the adoption and impact of $\mathrm{AI}$ in their business or professional life. $20 \%$ of the practitioners can be recognized as AI adopters in their professional life or business life. You can see it over here it that this percentage is far less than the percentage of usage of $\mathrm{AI}$ in their daily personal life. There is another finding that the male experts of AI are more than the female experts of AI. When the communication practitioners were asked about the impact of AI on their profession on a five point likert scale and surprisingly $76 \%$ of the professionals they chose the option that Artificial Intelligence will change the profession of communication totally.For the question of challenges that organizations can face, many potential challenges were given as options to choose and choice was given to them that they can choose more than one challenges. Challenges included Strategy development, how to utilize the skill set of communication professionals, people development, human judgement (that is done on the basis of combination of experience, intelligence and expertise, cost constraint and training. Budget (M 3.54) and Human judgement ( M 3.58) were selected mostly by the respondents for the potential challenges and very less respondents chose the option of human resource development. Communication Practitioners chose the risk of loss of identity ( 70 percent) and salary reduction ( $66 \%$ ) as the most potential risks that can be there for them in upcoming future whereas for the company owners or businessmen the risk factor for them is managing the skills of employees and other risk factor is cost of this technology. Strikingly, it is particularly the more youthful age, for example experts in their 20s that recognize these issues as potential dangers. Experts employed in non-profit associations are especially mindful of risks at the hierarchical level Hence overall it can be said that communication practitioners have limited information about Artificial Intelligence and budget is the biggest challenge for the businessmen or professionals to implement $\mathrm{AI}$ into their businesses or profession.

\section{Conclusion and Suggestion}

This study revealed that majority of the communication practitioners are agreeing that this Artificial Intelligence will bring the changes not only in communication profession but in every sort of professions that exist. Is AI an innovation that still can't seem to be completely perceived and embraced in communication profession? This study demonstrate that experts have followed the discussion in industry magazines however have not seen (or think about) any application of AI in their own association, division or organization, or in their own regular use. The equivalent goes by one way or another for the scholarly world: the rising interest of established researchers in AI has not arrived at the correspondence the communication discipline yet . Two bits of knowledge may be especially applicable for this profession: communication practitioners need to get to know AI and communication pioneers should perceive their duty regarding carrying out AI into their businesses. Suggestions 1 . First understand that there is differentiation between artificial intelligence and machine learning. Some people use it interchangeably. Notwithstanding the current publicity about AI and its incessant inclusion in industry magazines, most experts' ability on the innovation is fairly crude. So there is need for the top leaders to educate themselves firsts.2. Provide training to the employees to boost their knowledge about AI . 3. Build the gaps and enhance the communication. Numerous holes in comprehension regarding the advancement of computerized reasoning, however likely the greatest one is between organizations specialized specialists and political pioneers. Great public arrangements could diminish the adverse consequences of computerized reasoning without restricting the positive ones, the report closes - for instance, in the work market, 


\section{Limitations}

A few viewpoints ought to be mulled over while assessing the outcomes of our study. Since I chosen Punjab as the sampling area and it's a limitation so my study cannot be taken as statistically correct for communication practitioners because of the demographic limitation. The selected strategy just permitted us to evaluate view of communication experts. Their impression of difficulties and dangers may be one-sided by their idea of AI (despite the fact that we attempted to balance this by joining our definition into the survey) or by other frustrating factors that we didn't quantify. Additionally, we didn't find out if AI is now utilized in their correspondence division or organization, and if indeed, how much, as we expected a impressive measure of respondents would not have the option to respond to this.

\section{References}

1. Aziz, K. and Yusof, M.M. (2012), "Measuring organizational readiness in information systems adoption", paper presented at the Eighteenth Americas Conference on Information Systems (AMCIS), August 9-12, Seattle, Washington

2. Baccarini, D., Salm, G. and Love, P.E.D. (2004), "Management of risks in information technology projects", Industrial Management and Data Systems, Vol. 104 No. 4

3. Bill Holtsnider, Brian D. Jaffe, (2012), IT Manager's Handbook: Getting your new job done, third edition, U.S.A, Elsevier.

4. Brynjolfsson E. \& McAfee A. (2014). The second machine age: Work, progress, and prosperity in a time of brilliant technologies. New York, NY: WW Norton \& Company

5. Collister, S. (2016). "Algorithmic Public Relations: materiality, technology and power in a posthegemonic world", in L'Etang, J., McKie, D., Snow, N. and Xifra, J. (Eds.), The Routledge Handbook of Critical Public Relations, Routledge, London

6. Computer Law \& Security Review, 32(5), pp. 749-758.

7. Davison, W.P. (1983), "The third-person-effect in communication", Public Opinion Quarterly, Vol. 47 No. 1, pp. 1-15.

8. Dawar, N. and Bendle, N. (2018), "Marketing in the age of Alexa", Harvard Business Review, Vol. 96 No. 3, pp. 81-86.

9. DePietro, R., Wiarda, E. and Fleischer, M. (1990), "The context for change: organization, technology and environment", in Tornatzky, L.G. and Fleischer, M. (Eds.), The Processes of Technological Innovation, Lexington Books, Lexington, MA, pp. 151-175.

10. Dimitrieska, S., Stankovska, A. and Efremova, T. (2018), “Artificial intelligence and marketing”, Entrepreneurship, Vol. 7 No. 2, pp. 298-304.

11. Floridi, L., Cowls, J., Beltrametti, M., Chatila, R., Chazerand, P., Dignum, V., Luetge, C., Madelin, R., Pagallo, U., Rossi, F., Schafer, B., Valcke, P. and Vayena, E. (2018), "AI4People - an ethical framework for a good AI society: opportunities, risks, principles, and recommendations", Minds and Machines, Vol. 28 No. 4, pp. 689-707.

12. Gorden, s.1993. Standardization of information system and technology at multinational companies J. Global inform, management 1(3) 5-14.

13. I Goodfellow, Y. Bengio, and A. Courville. Deep Learning, The MIT Press, 2016.

14. Kaplan, A. and Haenlein, M. (2019), "Siri, Siri, in my hand: who's the fairest in the land? On the interpretations, illustrations, and implications of artificial intelligence", Business Horizons, Vol. 62 No. 1, pp. 15-25.

15. Kellogg, K.C., Valentine, M. and Christin, A. (2020), "Algorithms at work: the new contested terrain of control", The Academy of Management Annals, Vol. 14 No. 1, pp. 366-410.

16. King, K. (2019), Using Artificial Intelligence in Marketing: How to Harness AI and Maintain the Competitive Edge, Kogan Page, New York, NY.

17. Kose, U. and Sert, S. (2017), "Improving content marketing processes with the approaches by artificial intelligence", Ecoforum, Vol. 6 No. 1.

18. Lad Enterprizes, Inc., View Of Information Technology’s Relationship To Business, www.ladenterprizes.com, June 2008

19. Working Paper, ZHAW Z€urcher Hochschule f€ur Angewandte Wissenschaften, Winterthur, CH.

20. Nilsson, N.J. (1998), Artificial Intelligence: A New Synthesis, Morgan Kaufmann, San Francisco, CA.

21. Pare, G., Sicotte, C., Poba-Nzaou, P. and Balouzakis, G. (2011), "Clinicians' perceptions of organizational readiness for change in the context of clinical information system projects: insights from two cross-sectional surveys", Implementation Science, Vol. 6 No. 1, p. 15.

22. Penn, C.S. (2017), AI for Marketers: An Introduction and Primer, Trust Insights, Norfolk, MA.

23. Snow C.C. Fjeldstad Ø.D. Langer A.M. (2017). Designing the digital organization. Journal of Organization Design, 6(7), pp. $1-13$

24. Struhl, S. (2017), Artificial Intelligence Marketing and Predicting Consumer Choice: An Overview of Tools and Techniques, Kogan Page, London.

25. Wauters M. Vanhoucke M. (2015). A comparative study of Artificial Intelligence methods for project duration forecasting. 